\title{
Recollective experience and recognition memory for threat in clinical anxiety states
}

\author{
KARIN MOGG \\ University of Cambridge, Cambridge, England \\ and \\ JOHN M. GARDINER, ANDREAS STAVROU, and SUSAN GOLOMBOK \\ City University, London, England
}

\begin{abstract}
Recognition memory for threat and nonthreat words was examined in generally anxious patients in relation to normal control subjects. Two types of response in recognition memory ("know" and "remember") were used to test predictions from Williams, Watts, MacLeod, and Mathews's (1988) cognitive model of anxiety. The results failed to support the hypothesis that anxiety is associated with an implicit memory bias favoring threat (as measured by "know" responses) and an explicit memory bias against threat (as measured by "remember" responses). The findings are discussed in relation to recent research which suggests that there are two functionally independent systems within implicit memory.
\end{abstract}

According to the cognitive theories of Beck (Beck, Emery, \& Greenberg, 1985) and Bower (1981), anxiety is associated with a cognitive bias that favors threatening information, and this bias should be evident throughout processing activities, including encoding and retrieval. However, attempts to demonstrate a recall bias that favors threatening information in patients with generalized anxiety disorder have typically been unsuccessful (e.g., Mathews, Mogg, May, \& Eysenck, 1989; Mogg, Mathews, \& Weinman, 1987). In addition, no evidence has been found of a bias in recognition memory for threat words in generally anxious patients (Mathews \& MacLeod, 1985; Mogg et al., 1987; Mogg, Mathews, \& Weinman, 1989).

Although there does not appear to be a recall or recognition memory bias favoring threat information in clinical anxiety states, it has been established that generally anxious patients selectively attend to such material (see Mathews, 1990, for a review). These apparently discrepant findings cannot be accommodated by cognitive theories which assume that similar biases operate throughout all aspects of processing. However, Williams, Watts, MacLeod, and Mathews (1988) offered a potential theoretical resolution. Using Mandler's (1980) conceptual distinction between activation and elaboration, Williams et al. (1988) proposed that anxiety is associated with a cognitive bias favoring threat, which operates primarily in automatic, preattentive stages of processing (activation or implicit memory), rather than in later strategic, postattentive processes (elaboration

\footnotetext{
The work in this article was supported by grants from the Wellcome Trust and Medical Research Council. We are grateful to Stephen Critchlow for carrying out the diagnostic interviews. K. Mogg's address is Department of Experimental Psychology, University of Cambridge, Downing Street, Cambridge CB2 3EB, U.K. J. Gardiner's address is Memory and Cognition Research Group, City University, Northampton Square, London ECIV OHB, U.K.
}

or explicit memory). This formulation is consistent with the view that the primary function of anxiety is to facilitate the detection of threat stimuli, rather than to engage in extensive or elaborative processing of such material. Moreover, strategic, elaborative processes might be biased against threat in anxiety states. That is, anxious individuals may adopt a cognitive avoidance strategy that leads to reduced elaborative encoding of threat information, and this might explain why they occasionally show relatively poorer recall or recognition of such material (see, e.g., Mogg et al., 1987; Watts, Trezise, \& Sharrock, 1986).

In most research on memory bias in anxiety, explicit memory tests such as recall or recognition have been used. These require subjects to remember, in the sense of being able consciously to recollect, previously studied information. However, Mathews et al. (1989) assessed both explicit and implicit memory for threat and nonthreat words in anxious patients, who were compared with normal controls. They found no significant bias on a cued recall task. However, on a word-stem completion task, in which no reference was made to the previous study list (cf. Graf \& Mandler, 1984), anxious patients showed relatively greater priming for threat words. That is, anxious patients produced more threat completions, but only for words that had been seen in the earlier study phase. Since a significant bias was found on the implicit memory test of word-stem completion, but not on the explicit memory test of cued recall, enhanced activation (rather than elaboration) of memorial representations of threat is implicated as the cause. This finding is largely consistent with the predictions of Williams et al.'s (1988) model, although there was no evidence of poorer explicit memory for threat ("elaborative avoidance").

In light of these results, the absence of a bias for threat in recognition memory tests requires further consideration. According to Mandler (1980), recognition memory involves activation as well as elaboration, with activation 
giving rise to recognition based on feelings of familiarity, and elaboration giving rise to recognition based on specific recollective experience. Thus, Williams et al.'s (1988) theory can only account for the absence of a bias toward threat in recognition memory by assuming that the enhanced activation of threat words is completely offset by reduced elaboration (a 'tradeoff' hypothesis).

The present study was intended to provide further evidence on the question of whether or not there is a recognition memory bias in clinical anxiety states. Although previous studies have failed to yield any such bias in anxious patients, none of these studies was designed exclusively to test recognition memory (Mathews \& MacLeod, 1985; Mogg et al., 1987, 1989). The evidence from these studies may be rather equivocal because, for example, the recognition memory tests were secondary measures and overall levels of performance were therefore rather low. Thus, the present experiment was specifically planned for the investigation of recognition memory. An important aim in our study was to establish whether a recognition memory bias for threat information was present or absent in anxious individuals.

The most important difference between our study and previous ones was that recognition memory was measured by using two responses, "remember" and "know." These responses were introduced by Tulving (1985) to measure two kinds of conscious awareness. A "remember" response indicates that recognition of the word is accompanied by some specific recollective experience of the prior occurrence of the word in the study list. A "know" response indicates that recognition is not accompanied by any such recollective experience, but that it is based instead on a feeling of familiarity. For example, one can recognize a person as being familiar without remembering who the person is, or without being able to consciously recollect anything about that person.

Previous research has shown that these two measures reflect distinct components of recognition memory performance. Recognition accompanied by conscious recollection ("remember") is influenced by levels of processing (Gardiner, 1988), word frequency (Gardiner \& Java, 1990), divided attention (Gardiner \& Parkin, 1990), presentation mode (Gregg \& Gardiner, 1991), and intentionality (Macken \& Hampson, 1991), whereas recognition in the absence of conscious recollection ("know") is not influenced by these variables.

Tulving (1985) proposed that these two forms of recognition memory measured by "know" and "remember" responses are associated, respectively, with semantic and episodic memory systems. However, as Gardiner (1988) pointed out, these measures are also relevant to Mandler's (1980) theory, which proposes that activation gives rise to feelings of familiarity, whereas elaboration gives rise to recollective experience. Thus, as Macken and Hampson (1991) have also argued, it seems reasonable to assume that "know" responses reflect activation, and that "remember" responses reflect elaboration.

In summary, there were two main goals in the present study. First, we hoped to obtain more definitive evidence on the question of whether or not there is a recognition memory bias for or against threat words in anxious patients. Second, if no bias was found, we intended to test the "tradeoff" hypothesis by assessing "know" and "remember" responses. If there is selective activation of threat representations in anxious patients, they should show a relatively larger proportion of " $k$ now" responses to threat words. If anxious patients use an avoidance strategy that reduces elaborative encoding of threat stimuli and offsets the enhanced activation of such items, they should show a relatively smaller proportion of "remember" responses to threat words.

\section{METHOD}

\section{Subjects}

The anxious group consisted of 24 outpatients ( 16 female, 8 male; mean age, 38.3 years) with a primary diagnosis of generalized anxiety disorder according to DSM-III criteria; this was established in an interview with a consultant psychiatrist prior to referral to the study. The normal control group comprised 24 paid volunteers ( 16 female, 8 male; mean age, 37.7 years), who were mostly hospital employees. The two groups were matched for age, sex, and vocabulary level as measured by the Mill Hill Vocabulary Synonyms test. On the Spielberger State-Trait Anxiety Inventory, the anxious group obtained significantly higher state and trait anxiety scores than did controls [mean scores for anxious and control groups were $\mathbf{4 5 . 0}$ and 33.0, respectively, for state anxiety, $t(46)=3.2, p<.01$, and 54.3 and 37.4 for trait anxiety, $t(46)=6.6, p<.001]$.

\section{Materials}

There were 64 stimulus words. Half were rated by 10 judges as being related to threat and half were rated as being unrelated to threat. Half of the threat words were related to physical threat (e.g., accident, fatal, violence) and half to social threat (e.g., unloved, embarrassed, insult); half the nonthreat words were positive (e.g., applause, fortunate, delight) and half were neutral (e.g., bathroom, recipe, varnish). (Cf. Mathews et al., 1989.) The word sets were matched for word length and frequency. Each word set was divided in half to provide two alternate study lists, each consisting of 16 threat and 16 nonthreat words (the two study lists were matched for word length, frequency, and threat value). Half of the subjects in each group received one study list; half received the other. The recognition test consisted of all 64 words. Thus, target words for half the subjects were lure words for the other half.

\section{Procedure}

The procedure for the study task and recognition test was modeled on that used by Gardiner and Java (1990). Study-list words were presented on a deck of cards in a new random order for each subject, at a rate of one word every $2 \mathrm{sec}$. The subjects were told to attend carefully to each word because there would be a memory test for the words later in the session. After the study task, there was a 10-min retention interval, during which the subjects completed the State-Trait Anxiety Inventory.

For the recognition memory test, the subjects were given a sheet with all 64 words typed in a fixed random order. The subjects were told to draw a circle around each word that they recognized from the study cards. The test was preceded by additional instructions for "know" and "remember" responses (Gardiner, 1988; Gardiner \& Java, 1990). The subjects were told that when they recognized each word, they were also to write an " $R$ " for "remember" if their recognition of the word was accompanied by a conscious recollection of its prior occurrence in the study list, or a " $K$ " for " $k$ now" if they did not consciously recollect the word's occurrence in the study list but recognized it on some other basis. "Remember" was defined as the ability to become consciously aware again of some aspects of what happened or what was experienced when the word was presented, such as aspects of the physical appearance of the word, or of something that happened in the room, or of something one was thinking or doing at the time. "Know" responses were defined as the recognition of the word but the inability to recollect consciously anything about its actual occurrence or what happened or what was ex- 
perienced at the time of its occurrence. This distinction between "know" and "remember" responses was illustrated with more everyday examples (see Gardiner \& Java, 1990).

Finally, subjects completed the Mill Hill Vocabulary Synonym test.

\section{RESULTS}

Table 1 summarizes the main results, which are the mean numbers of "remember" and "know" responses to recognition targets and lures, calculated separately for threat and nonthreat words within each group. Overall hit scores were obtained by summing "know" and "remember" responses to targets; overall false alarm scores are the sum of "know" and "remember" responses to lures.

A repeated measures analysis of variance (ANOVA) of responses to targets (hits) was carried out with two withinsubject factors, response type ("know" vs. "remember") and word valence (threat vs. nonthreat), and one betweensubject factor of group (anxious vs. control). Only effects and interactions involving group will be reported from the main analyses, since these results are directly relevant to the hypotheses under consideration. The interaction between group and word valence was not significant $[F(1,46)$ $=0.09$, n.s.]. This null result for overall hit scores (summed across "know" and "remember" responses) is consistent with previous failures to find a recognition memory bias for threat in anxious patients. Furthermore, there was no significant group $\times$ word valence $\times$ response type interaction $[F(1,46)=1.00$, n.s. $]$, which fails to support the tradeoff hypothesis.

A separate ANOVA of "know" responses to targets was carried out to test the specific hypothesis of enhanced activation of threat words in anxious subjects. The predicted group $\times$ word valence interaction was not significant $[F(1,46)=1.07$, n.s. $]$. A separate ANOVA of "remember" responses to targets was conducted to test the specific hypothesis of reduced elaboration of threat in anxious patients. This critical group $\times$ word valence interaction was also not significant $[F(1,46)=0.39$, n.s. $]$.

It could be argued that these results for responses to targets (hits) may be confounded by response bias effects that would be apparent in the false alarm data. However, the level of false alarms was deemed too low to justify separate statistical analyses. Thus, to provide a measure of memory that would take account of response bias, we calculated for each subject the difference between hit and false alarm scores within each response-type/word-valence condition (see Table 1 for means). An ANOVA of these scores produced the same pattern of results as that found for hit scores. Hence, the null findings cannot be attributed to response bias effects.

Subsidiary analyses were carried out to examine effects due to the four different word types (positive, neutral, social threat, and physical threat) on "know" and "remember" responses. A repeated measures ANOVA of responses to targets, which included the factors of word type (four levels) and response type ("know" vs. "remember"), showed no significant interactions involving group. Although there were no significant main effects due either to word type or to response type, there was a significant word type $\times$ response type interaction $[F(3,44)=$ $5.38, p<.01]$, which seemed of theoretical interest. To clarify this interaction, separate ANOVAs of "know" and "remember" responses to targets were carried out. These showed a significant main effect of word type on "remember" responses $[F(3,44)=7.64, p<.001]$, but not on "know" responses $[F(3,44)=1.38$, n.s. $]$. The effect of word type on "remember" responses to targets was illustrated by post hoc contrasts showing that subjects generally gave more "remember" responses to neutral words relative to positive $[F(1,46)=5.89, p<.05]$, social threat $[F(1,46)=22.62, p<.01]$, or physical threat words $[F(1,46)=5.31, p<.05]$. Across all subjects, the mean numbers of "remember" responses for neutral, positive, social threat, and physical threat target words were $3.3,2.4,1.6$, and 2.5 , respectively; the mean numbers of "know" responses for these target word types were $2.0,2.2,2.5$, and 2.4 , respectively.

Similar analyses were carried out for difference scores (i.e., hits minus false alarms within each condition), in order to examine the effect of word type. These yielded the same pattern of results as that found for hit scores, which indicated that the general effects of word type on "remember" rather than "know" responses were not accounted for by response bias effects.

\section{DISCUSSION}

\begin{abstract}
The first goal of this study was to establish whether or not there is a recognition memory bias favoring threat words in clinical anxiety. Clearly, no evidence for such a bias was found. Taken together with previous null findings (Mathews \& MacLeod, 1985; Mogg et al., 1987, 1989), the absence of a recognition memory bias favoring threat in clinical anxiety states now seems quite firmly established.

The second goal of the study was to use "remember" and "know" responses to test the "tradeoff' hypothesis, which sought to explain the absence of a recognition memory bias in anxiety by suggesting that the enhanced activation of threat words is offset by reduced elaboration. The present results provided no support for this hypothesis.
\end{abstract}

Table 1

Mean Number of "Remember" and "Know" Responses to Threat and Nonthreat Targets and Lures for Each Group

\begin{tabular}{|c|c|c|c|c|c|c|c|c|c|c|c|c|}
\hline \multirow[b]{3}{*}{ Subjects } & \multicolumn{4}{|c|}{ Targets } & \multicolumn{4}{|c|}{ Lures } & \multicolumn{4}{|c|}{ Difference Scores } \\
\hline & \multicolumn{2}{|c|}{ "Know" } & \multicolumn{2}{|c|}{ “Remember" } & \multicolumn{2}{|c|}{ "Know" } & \multicolumn{2}{|c|}{ "Remember"' } & \multicolumn{2}{|c|}{ "Know" } & \multicolumn{2}{|c|}{ "Remember" } \\
\hline & Threat & $\begin{array}{l}\text { Non- } \\
\text { threat }\end{array}$ & Threat & $\begin{array}{l}\text { Non- } \\
\text { threat }\end{array}$ & Threat & $\begin{array}{l}\text { Non- } \\
\text { threat }\end{array}$ & Threat & $\begin{array}{l}\text { Non- } \\
\text { threat }\end{array}$ & Threat & $\begin{array}{l}\text { Non- } \\
\text { threat }\end{array}$ & Threat & $\begin{array}{l}\text { Non- } \\
\text { threat }\end{array}$ \\
\hline Anxious patients & 4.6 & 4.2 & 4.3 & 5.7 & 1.1 & 0.9 & 0.5 & 0.2 & 3.5 & 3.3 & 3.8 & 5.5 \\
\hline Normal controls & 5.3 & 4.0 & 3.9 & 5.8 & 1.5 & 0.5 & 0.5 & 0.3 & 3.8 & 3.5 & 3.4 & 5.5 \\
\hline
\end{tabular}

Note-Responses to targets are hits; responses to lures are false alarms; difference scores $=$ hits - false alarms. 
The absence of a bias in "remember" responses failed to support the specific prediction of reduced elaboration (or a cognitive avoidance strategy) for threat information in anxious patients. This null finding suggests instead that no bias operates in elaborative processes, either for or against threat stimuli. Although the present results did not confirm the cognitive avoidance hypothesis, the absence of any elaborative bias is at least consistent with the suggestion that the functional significance of anxiety is restricted to the detection of threat stimuli, rather than to their further analysis (Mathews, 1990; Williams et al., 1988).

However, the failure to demonstrate a bias in "know" responses to threat words may be regarded as raising problems with respect to Williams et al.'s (1988) model, which specifically predicts that anxiety-related biases should be apparent on implicit memory tests that reflect activation. This null finding also seems inconsistent with the implicit memory test results of Mathews et al. (1989), which showed greater priming in word-stem completions for threat words in anxious patients (i.e., increased activation of threat representations).

However, the discrepancy between the present results and those of Mathews et al. (1989) may be resolved by considering recent theoretical developments in the study of implicit memory processes. Tulving and Schacter (1990) have argued that there are two independent types of priming effects in implicit memory: perceptual and conceptual priming. They argue that perceptual priming is an expression of a perceptual representation system (PRS), which is concerned with the identification of perceptual objects (including words) and which operates at a presemantic level. In contrast, conceptual priming reflects a process of semantic learning: the modification of, or addition of new information to, semantic memory.

Recent evidence suggests that "know" responses in recognition memory may reflect perceptual, rather than conceptual, priming effects in priming memory. For example, Gardiner and Java (1990) found enhanced recognition in the absence of conscious recollection for nonwords as opposed to words (i.e., a higher level of correct "know" responses for nonwords than for words), which clearly cannot be explained by conceptual priming effects within implicit memory. The results of the subsidiary analyses in the present study also appear to be consistent with this view, since there was a significant effect of word type on "remember" responses, but not on "know" responses. This suggests that "know" responses were unaffected by the semantic or conceptual characteristics of the words. Thus, it seems reasonable to conclude that "know" responses primarily reflect perceptual rather than conceptual implicit memory effects (see also Gardiner \& Parkin, 1990). The absence of the predicted bias in "know" responses might then be explained by the fact that threat words are primarily distinguished from a category of nonthreat words by their conceptual (not perceptual) characteristics, and that this particular implicit memory measure is insensitive to such information.

In contrast, other implicit memory measures, such as primed wordstem completions, may provide a better indicator of conceptual, rather than perceptual, implicit memory operations. For example, priming effects involving the acquisition of new associations between unrelated words have been observed on word-stem completion and free association tests in normal subjects following semantic study processing (Graf \& Schacter, 1985; Schacter \& McGlynn, 1989). Thus, the priming effect of threat information on word-stem completions found by Mathews et al. (1989) might reflect a bias in conceptual (rather than perceptual) implicit memory processes in clinical anxiety.

In conclusion, the limited evidence that is so far available seems to suggest that anxiety is associated with a cognitive bias favoring threat which operates primarily in conceptual implicit memory, rather than in other types of implicit memory, such as the perceptual representation system. This interpretation, which is clearly speculative, needs to be evaluated in further research. For example, the same sample of anxious and nonanxious subjects could be assessed on both word-stem completions and recognition "know" responses for threat and nonthreat words, in order to establish whether these tasks produce independent effects within implicit memory.
Williams et al. (1988) have cogently argued that theoretical developments in experimental cognitive psychology, such as the distinction between explicit and implicit memory, may help to improve our understanding of the role of cognitive processes in the etiology and maintenance of emotional disorders. However, as Tulving and Schacter (1990) have pointed out, we still know relatively little about implicit memory. Moreover, there is growing evidence to suggest that implicit memory may involve at least two functionally independent memory systems. It is apparent that this needs to be taken into account in future research on the nature of cognitive bias in anxiety.

\section{REFERENCES}

Beck, A. T., Emery, G., \& Grennerg, R. (1985). Anxiety disorders and phobias: A cognitive perspective. New York: Basic Books.

Bower, G. (1981). Mood and memory. American Psychologist, 36, 129-148.

GARDINER, J. M. (1988). Functional aspects of recollective experience. Memory \& Cognition, 16, 309-313.

GARDINER, J. M., \& JAVA, R. I. (1990). Recollective experience in word and nonword recognition. Memory \& Cognition, 18, 23-30.

GARDINER, J. M., \& PARKIN, A. J. (1990). Attention and recollective experience in recognition memory. Memory \& Cognition, 18, 579-583.

GraF, P., \& MANDler, G. (1984). Activation makes words more accessible, but not necessarily more retrievable. Journal of Verbal Learning \& Verbal Behavior, 23, 553-568.

GrAF, P., SCHACTER, D. L. (1985). Implicit and explicit memory for new associations in normal and amnesic subjects. Journal of Experimental Psychology: Learning, Memory, \& Cognition, 11, 501-518.

GrEGG, V., \& GARDINER, J. M. (1991). Components of conscious awareness in a long-term modality effect. British Journal of Psychology, 82, 153-162.

MACKEN, W., \& HAMPSON, P. (1991). Integration, elaboration and recollective experience. Manuscript submitted for publication.

MANDLER, G. (1980). Recognizing: The judgment of previous occurrence. Psychological Review, 87, 252-271.

Mathews, A. (1990). Why worry? The cognitive function of anxiety. Behavior Research Therapy, 28, 455-468.

Mathews, A., \& MACLEOD, C. (1985). Selective processing of threat cues in anxiety states. Behaviour Research \& Therapy, 23, 563-569.

Mathews, A., Mogg, K., May, J., \& Eysenck, M. (1989). Implicit and explicit memory bias in anxiety. Journal of Abnormal Psychology, 98, 236-240.

Mogg, K., Mathews, A., \& Weinman, J. (1987). Memory bias in clinical anxiety. Journal of Abnormal Psychology, 96, 94-98.

Mogg, K., Mathews, A., \& Weinman, J. (1989). Selective processing of threat cues in anxiety states: A replication. Behaviour Research \& Therapy, 27, 317-323.

SCHACTER, D. L., \& MCGLYNN, S. M. (1989). Implicit memory: Effects of elaboration depend on unitization. American Journal of Psychology, 102, 151-181.

Tulving, E. (1985). Memory and consciousness. Canadian Psychologist, 26, 1-12.

Tulving, E., \& SChaCter, D. L. (1990). Priming and human memory systems. Science, 247, 301-306.

Watts, F., Trezise, L., \& Sharrock, R. (1986). Processing of phobic stimuli. British Journal of Clinical Psychology, 25, 253-261.

Williams, J. M. G., Watts, F., Macleod, C., \& Mathews, A. (1988). Cognitive psychology and emotional disorders. Chichester, U.K.: Wiley.

(Manuscript received August 14, 1991.) 